\title{
Analyzing reverse logistics in the Brazilian National Waste Management Policy (PNRS)
}

\author{
M. M. Veiga ${ }^{1,2}$ \\ ${ }^{1}$ Environmental Health Department, National School of Public Health, \\ Oswaldo Cruz Foundation, Ministry of Health, Brazil \\ ${ }^{2}$ Strategic Management Department, Business School, \\ Federal University of Rio de Janeiro State, Ministry of Education, Brazil
}

\begin{abstract}
In the last 20 years, the Brazilian population has increased by $30 \%$, while the amount of waste has risen by $90 \%$. This demographic expansion associated with an increasing consumption of disposable products has switched the type (quality and quantity) of waste produced. Currently, many municipalities are facing difficulties in finding appropriate disposal sites. As a result, waste management has become a national priority. In 2010, after been on hold in the Nation's Congress for decades, the National Waste Management Policy (PNRS) was approved through formal legislation (Law 12.305/10). The PNRS represented a major political and judicial improvement, but, still, represents a major economical and operational challenge. The strategies for improving waste management in Brazil should include instruments provided in the PNRS. Extended product responsibility, which includes all supply chain stakeholders, and reverse logistics are two main instruments incorporated in PNRS. A postconsumption reverse logistics program is the most common strategy to make operational the extended producer responsibility concept. Usually, a reverse logistics program deals with a specific range of products requiring by legal enforcement to be: recycled; reused; remanufactured; finally disposed of; treated; or incinerated. An efficient reverse logistics program should stimulate producers to internalize all social and environmental costs, from cradle to grave, in their decision making process. Thus, it is necessary to analyze the costs and benefits of PNRS instruments in order to balance benefits (reducing social and environmental damages) and costs (keeping reverse logistics chain operational). Legislation is the most common instrument to change market behavior in order
\end{abstract}


to improve efficiency in returning numerous products. Even tough, reverse logistics has been successfully introduced in several national public policies; the instrument is still pending a further boost in the Brazilian regulatory system. This study discusses the strategies included in the PNRS.

Keywords: waste management, reverse logistics, extended producer responsibility, Brazil.

\section{Introduction}

In the last 20 years, Brazilian population has increased by $30 \%$, while the amount of waste has risen by $90 \%$. This demographic expansion associated with an increasing in the consumption of disposable products has switched the type (quality and quantity) of waste produced. Therefore, waste management is becoming a national priority for public officials $[1,2]$.

Currently, many municipalities are facing difficulties in finding adequate disposal sites. This site shortage for placing solid waste disposal facilities has leaded to inefficient logistics operations, and increasing environmental, social and economical costs [3].

Recycling, composting and reusing should be the natural alternatives for disposing waste, as they are associated with lower environmental impacts. Incineration, which has high costs, produces gas, ash and effluents should be the least desirable alternative [4-7].

Irregular and heterogeneous waste mix makes it difficult for recycling and composting processes to be economically feasible. High operational costs are usually linked to inefficient composting and recycling processes. Mixed waste needs to be segregated to improve technical efficiency, compost and recycled material quality. Most of the times, the use of low quality recycled material by industry is costly comparatively to the use of equivalent raw material [8].

In an attempt to reduce uncontrolled waste mix, many countries have implemented selective collection and recycling programs, which motivate segregation. Zhuang et al. [9] have indicated that segregation is a key component for improving the overall efficiency of any waste management process.

In Brazil, most of the selective collection and recycling programs are inefficient, with the exception of those in which the value of the material recycled is economical viable, which makes the whole reverse logistics chain efficient, e.g. aluminum and paper.

Due to these logistics difficulties, landfills are still the most common solution for disposing solid waste. Cost-benefit analysis indicated that landfills have comparatively low operational costs and simpler technical standards [10].

Thus, an increase in recycling and in composting would elevate existing landfill life, postponing the need for new disposal facilities. Due to the increase in waste generation ratio, public officials should prioritize investments in preventing (reduce waste generation) instead of just building more disposal facilities [11].

In Brazil, landfill disposal is still an exception. Most of the urban waste is disposed in illegal dumps. However, the PNRS dictated that all illegal dumping 
should be eradicated by 2014. The PNRS is the major Brazilian attempt to properly manage waste.

\section{The national waste management policy (PNRS)}

In Brazil, the first waste management regulations dated 25 years ago. Since the 80 s, much legislation has been enacted. These regulations were not integrated, they were disperse throughout many legislative instruments, e.g. laws; administrative orders; and resolutions. This complex regulatory system made surveillance a hard task and had many conflicting legislation.

In 2010, after been on hold in Nation's Congress for decades, the National Waste Management Policy (PNRS) was approved through formal legislation (Law 12.305/10). The PNRS represented a major political and judicial improvement, but, still, represents a major economical and operational challenge.

PNRS promotes efficiency by stimulating innovation in waste management strategies and actions. There are three major instruments in the PNRS to implement and improve efficiency of waste management: Extended Producer Responsibility (EPR); Sectoral Agreement (SA); and Reverse Logistics (RL).

EPR establishes a shared responsibility among all stakeholders in the supply chain (suppliers-producers-consumers) throughout all product life cycle. It demands internalization of environmental costs in the decision making process of the supply chain.

In order to make EPR operational, PNRS requires a Sectoral Agreement (SA), which incorporates negotiation and contractual concept. It is a negotiation among public sector, producers, suppliers, importers, and dealers to implement EPR throughout product life cycle. Currently, these sectoral agreements are being negotiated.

PNRS strategy makes all stakeholders liable, internalizing environmental costs and stimulating innovation. The reverse logistics (RL) is the process of introducing recycled material after consumption on the supply chain. The reverse logistics is one main instrument of the PNRS (see figure 1).

Forward Logistics

Forward Logistics

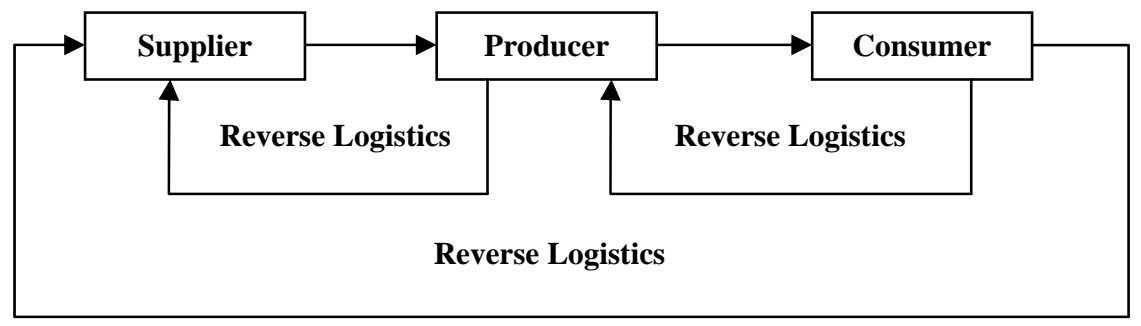

Figure 1: $\quad$ Forward and Reverse Logistics flow.

The complete supply chain incorporates forward logistics activities (production, distribution, and consumption) and reverse logistics activities 
(collection, inspection, segregation, reprocess, recycle, and disposal). It is every stakeholder responsibility planning and operating this post consumption reverse logistics chain [12-14].

In most cases, even though it is not required, the stakeholders in the reverse logistics can be different from those in the forward logistics. Consumers operate in both edges of the supply chain, by returning post consumed products and by buying recycled products. Usually, suppliers and producers take into service third parties to make the reverse logistics operational. This strategy might be related to economical and technical issues [15].

The PNRS require the organization and the implementation of reverse logistics flow for producers, importers, distributors and retailers of selected products: pesticides (residues and containers); batteries; tires; lubricants (residues and containers); fluorescent lamps; and e-waste. This legal required reverse chain should comply with the sectoral agreement; consider technical and economical viability, social and environmental impacts.

The efficiency of any reverse logistics program is directly related to an efficient recycled material market. The PNRS states that it is producers, importers, distributors and retailers responsibility to implement: procedures for marketing empty containers and residues; receiving units for recyclable products; and partnership with recycling cooperatives.

However, the success of the PNRS is associated with the implementation of the extended producer responsibility (EPR), making liable any stakeholders of the supply chain (reverse and forward). The initiative for starting the reverse logistics relies on the consumer. A successful reverse logistics programs should stimulate end users to trigger the process.

OECD highlighted two related aspects of any EPR policy: "(1) the shifting of responsibility (physically and/or economically; fully or partially) upstream toward the producer and away from municipalities, and (2) to provide incentives to producers to incorporate environmental considerations in the design of their products” $[16,17]$.

Some economic instruments commonly associated to the effectiveness and the efficacy of reverse logistics is: Deposit and Refund Schemes; Advance Disposal Fees; Material Taxes; Upstream Combination Tax and Subsidy. Costbenefit analysis of reverse supply chain should weight and balance benefits (reducing social costs of waste management) against the costs incurred in making the program operational [16].

Consequently, economics play a great role in making an efficient reverse supply chain. An efficient reverse logistics should be the one that is preferred over several alternative policy instruments. In the waste management decisionmaking process, there is a need for identifying, designing, and implementing cost-effective instruments by balancing economic, legal and environmental aspects. Reverse logistics is an instrument of EPR policy that makes operational taking back product or its packing after use [16-18]. 


\section{Reverse logistics}

Reverse and forward logistics are not differentiated in terms of operational aspects. Many particularities of reverse logistics have been continuously ignored. Forward logistics is an active process, where firms plan, produce, and supply distributors with products based upon forecasts. Reverse logistics is a reactive process with more unpredictable factors, which is usually initiated by end-user. The main trigger for reverse logistics process is the end-user, not the manufacturers themselves $[12,19]$.

Recent literature highlighted the importance of integrating all these processes. Stock [20] stated that successful reverse logistics solutions could only occur by efficiently merging forward and reverse flows into one process. Krikke et al. [29] ratified the need for a strong integration between forward and reverse chain.

Brito and Dekker [15] stated that reverse logistics is conceptually different from waste management. Waste management deals with effectively managing waste and its legal and environmental consequences. This assumption was only possible by defining waste in a controversial way, as products that have no value to be recovered. Reverse logistics, as a concept, focus on products that have some value to be recovered, creating a valued supply chain. A deeper conceptual discussion on the definition of term "waste" and its relation to supply chain theory can be found in Hicks et al. [21].

Many studies analyzed reverse logistics experiences in different countries [12, $19,22,23]$ which explicitly highlighted differences in motivation in several takeback programs (environmental, economical, and legal motivations). These different motivations have direct influence in the management strategy of reverse logistics process flow.

Similarly to PNRS, many regulatory systems have already incorporate reverse logistics in their environmental system. The different motivations for returning consumed or after-used goods could vary from environmental, economical, and legal aspects. Each real world situation should weight and balance these different issues $[12,19]$.

Reverse logistics in the PNRS is legislation-driven strategy; however, the economic aspects are important for the overall success. Legal compliance could be costly and require stakeholders finding viable alternatives for final disposal, which sometimes implies economical losses. However, high logistics costs should not be an excuse for non-complying with legal requirements [12, 19].

The strategy used in any logistic system can have a great impact on its economical, legal, and environmental efficiency. Outcomes in reverse logistics channels for recycling are connected to logistics costs (collection costs and recyclers services). Logistics costs are a large part of total recycling costs, reported as much as $95 \%$. One strategy commonly used by decision makers for saving logistic costs is postponement [24, 25].

The postponement principle was originally introduced in the 50s as a strategy for structuring Marketing Distribution Channels involving inventories delays on forward logistics theory [26]. However, recent theory on postponement also included reverse logistics activities, specially relating to differentiation of goods. 
This "improved" postponement theory incorporated diverse strategy aspects like collection versus sorting complexity, and segregation versus co-collection. In reverse channels, postponement of transformation activities (separation) might have greater importance than postponement of transfer activities (transport), [24].

The logic behind postponement is that the costs associated to risks and uncertainties are related to goods differentiation that occurs during the logistic process. The postponement/speculation strategy indicates that speculative inventories will be created in the logistic process "if the costs of such inventories are less than the savings from postponement”. Postponing to final stages might entail savings in transportation and inventory costs by sorting products in "large lots" and in "undifferentiated states" [26, 27].

In forward logistics channels, smaller volumes of different products are transported together to reduce cost. In reverse channels, materials can be cocollected by using compartmentalized vehicles; by alternate scheduling; or by bagging different materials. In case of toxic products, like pesticide and lubricants containers, postponement can increase risk of contamination [24, 25].

Postponement and speculation principle can also affect the length of the reverse logistic channel. If speculation takes place and materials are co-collected, transfer levels (intermediary disposal units) are often introduced to sort and store some of the fractions. In reverse channels, speculation leads to smaller volumes of each fraction being transported, resulting in higher transportation costs and low capacity utilization $[24,25]$.

Therefore, differentiation is a keyword for efficiently applying postponement and speculation strategy in reverse logistic channels. Speculation in reverse channels leads to smaller volumes of each fraction being transported and thus resulted in higher transportation costs. Many fractions separated (segregation) early in the collection level can be considered speculation. The more fractions sorted at collection level, improve recyclable quality, but are more challenging for collecting and transporting activities.

\section{Discussion}

It is a hard task to implement an economically viable reverse logistics program in such a large country like Brazil. The recyclable materials market is still developing and is also widely disperse. There are just a few buyers, mostly concentrated in large cities, and numerous sellers spread all over the country. Transportation costs make most of recyclable materials transactions unbeneficial compared to the equivalent price of raw materials.

The recyclable market has a lot of uncertainties, especially those related to seasonality and quality of recyclable materials. These variables increase industrial costs of using recyclable materials in most products that have a higher aggregate value associated. For that reason, in order to make recyclables competitive, there is a market force to drop the price for these seasonable, mixed, and poor in quality recyclable materials. Most recycled materials (e.g. plastics) are used in low value-added products. 
In large communities, economy of scale can be applied [28]. In these cases, speculation and segregation should be considered in order to increase the quality and the homogeneity (reduction of mix) of recyclable materials. These actions would increase the recyclable value, make it feasible for most industries, and turn the reverse chain profitable. The Brazilian aluminum cans reverse chain is a good example of this profitable market. Brazil recycles around $97 \%$ of aluminum cans, without any legislation to enforce it.

However, most of recyclable markets in Brazil are not profitable and need some coercive and enforcement power to change industry behavior in using low quality recyclable materials. The legislative strategy is that by enforcing industry to use recyclable materials, it will create a recycling market, which would lead to improvements in the efficiency of this reverse chain. If they are required to use, industry would also organize this reverse supply chain in order to receive better quality recyclable materials.

Nevertheless, this industry requirement for using low quality recyclable materials in their production line should be gradually introduced. This action would stimulate industrial intervention on chaotic reverse supplies, creating a great opportunity for innovation. Market creation is a requirement for reverse chain to operate efficiently.

On the other hand, small markets tend to be unprofitable no matter what. It is almost impossible for them to operate in economy of scale or in economy of scope. Postponement and storage centers might be an alternative to make these small markets viable.

In order to reduce transportation costs, some products collected from different sites might need to be mixed in temporary storages; there should be a segregation stage before final processing the recycled material. In order to increase the amount recovered from each material; there should be incentives for end users to return products into the reverse chain.

Another alternative for collecting small quantities is using compartmentalized vehicles or bagging the products. This type of collection requires intermediate storage space for each different product and postponing segregation phase making it more complex and costly. For sanitary reasons, it is not viable to mix in the same trucks toxic and non toxic products.

Finally, legal requirements such as the ones present in the PNRS are still necessary to boost and to implement most reverse chains. The EPR concept makes liable any stakeholders in the supply chain (forward and reverse). It is still under negotiation the Sectoral Agreements from each industry. These agreements will guide enforcement of EPR in the PNRS.

However, many industries have already started to develop their reverse logistics programs. The postponement and speculation strategy should be combined depending on the type and the amount of material. There is still pending further studies for the best alternative of reverse logistics for each industry, which will depend on the result of the sectoral agreement negotiation. Different industries should use different strategies. 


\section{Conclusion}

The main objective of this study was to analyze reverse logistics in the Brazilian National Waste Management (PNRS). The shared liability (EPR) enables the creation of reverse chain by making all stakeholders responsible for products life cycle. In Brazil, the current reverse logistics programs are incipient and need to be boosted.

However, reverse logistics strategy should not be simplified as just a "shared responsibility" implementation. Public policy should stimulate innovation and enforce law compliance. The way EPR was introduced in the PNRS does not seem to promote innovation, especially on primary and secondary prevention activities. Also, PNRS do not require life cycle analysis and product reengineering. The success of PNRS relies on negotiation (sectoral agreement), which might be considered a battle between environmental protectors and economic developers.

The shared liability among all stakeholders stimulates incorporating environmental costs in the decision making process. It would also make possible for producers to innovate by changing their products and processes, associating the concept of designing for recycling or designing for the environment.

However, the industry might not improve reverse supply chain without compulsory demand for innovation. It is most likely that industry will advocate for "business as usual" strategy. This strategy will not stimulate recyclable markets or reuse products. It could create incentives for less desirable disposable alternatives, such as incineration.

There are some weaknesses on the PNRS that could jeopardize its intent to promote innovative initiatives. In the PNRS, the economic incentives are mostly facultative and there is no instrument to stimulate cooperation. Depending on the sectoral agreements outcome, it is still uncertainty if the required reverse supply chain development will be feasible.

The PNRS tries to improve reverse logistics chain by providing economic incentives, such as: prioritizing recyclables; subsidizing selective collection; and financing recycling and reusing industries. The main PNRS targets should be: avoid and/or reduce waste generation; reuse whenever possible; create a recyclable market; treat and dispose properly. In order to improve reverse supply chain efficiency is mandatory to create a recyclable market.

An alternative to improve waste management efficiency is to increase recycling and composting ratio. An efficient policy should incorporation action to reduce waste generation. The public policy should stimulate recycling market by setting proper economic incentives. Producers should be required to increase gradually their use of recyclable materials in their product line. Strategic policies to reduce waste generation should focus on producers and consumers. Producers should be stimulated to innovate and to change their processes. Consumers should be stimulated to alter their consumption patterns.

In order to make supply chain operational, in products with higher value added, speculation can be applied because transportation costs do not represent a major barrier. In this case centralized storage could be used. In low value 
products, transporting long distances could make the reverse chain unprofitable. Therefore, there is a need for a more decentralized system, with smaller storage centers. In this case, postponement could be applied efficiently.

Public policies, like the National Waste Management Policy (PNRS) played an important role in implementing reverse logistics chains. In order to make PNRS more operational, the shared responsibility (EPR) should be enforced by using coercive power to change stakeholders' behavior. This public enforcement power is associated to the sectoral agreement, which is, currently being negotiated.

\section{Acknowledgement}

Thanks go to FAPERJ, Capes, and CNPq for the financial support.

\section{References}

[1] IBGE. Pesquisa nacional de saneamento básico. Rio de Janeiro: IBGE, 1989.

[2] IBGE. Pesquisa nacional de saneamento básico. Rio de Janeiro: IBGE, 2008.

[3] Günther, W.M.R. Resíduos sólidos no contexto da saúde ambiental. São Paulo: Universidade de São Paulo. Departamento de Saúde Ambiental da Faculdade de Saúde Pública, 148p. 2008.

[4] Denison, R.A. Environmental life-cycle comparisons of recycling, landfilling and incineration: a review of recent studies. Annual Review of Energy and the Environment, v. 21, p. 191-237, 1996.

[5] Valerio, F. Environmental impacts of post-consumer material managements: Recycling, biological treatments, incineration. Waste Management, v. 30, p. 2354-2361, 2010.

[6] Meneses, M.; Schuhmachera, M.; Domingo, J.L. Health risk assessment of emissions of dioxins and furans from a municipal waste incinerator: comparison with other emission sources. Environment International, v. 30, p. 481-489, 2004.

[7] Morselli, L.; Robertis, C.; Luzi, J.; Passarini, F.; Vassura, I. Environmental impacts of waste incineration in a regional system (Emilia Romagna, Italy) evaluated from a life cycle perspective. Journal of Hazardous Materials, v. 159, p. 505-511, 2008.

[8] Bohm, RA; Folz, DH; Kinnaman, TC; Podolsky, M.J. The costs of municipal waste and recycling programs. Resources, Conservation and Recycling, v. 54, p. 864-871, 2010.

[9] Zhuang, Y.; Wu, S.W.; Wang, Y.L.; Wu, W.X.; Chen, Y.X. Source separation of household waste: A case study in China. Waste Management, v. 28, p. 2022-2030, 2008.

[10] Giusti, L. A review of waste management practices and their impact on human health. Waste Management, v. 29, p. 2227-2239, 2009. 
[11] Kinnaman, T. The economics of municipal solid waste management. Editorial. Waste Management, v. 29, p. 2615-2617, 2009.

[12] Fleischmann, M.; Bloemhof-Ruwaard, J.M.; Dekker, R.; Van Der Laan, E.; Van Nunen, J.A.E.E.; Van Wassenhove, L.N. Quantitative models for reverse logistics: a review. European Journal of Operational Research, v. 103, p. 1-17, 1997.

[13] Guide J.R., V.D.R.; Jayaraman, V.; Linton, J.D. Building contingency planning for closed-loop supply chains with product recovery. Journal of Operations Management, v. 21, p. 259-279, 2003.

[14] Kumar, S.; Putnam, V. Cradle to cradle: Reverse logistics strategies and opportunities across three industry sectors. International Journal of Production Economics, v. 115, p. 305-315, 2008.

[15] Brito, M.P.; Dekker, R. A framework for reverse logistics. Rotterdam: ERIM, 2003. 29p.

[16] Organisation for Economic Co-operation and Development (OECD). Analytical Framework for Evaluating the Costs and Benefits of Extended Producer Responsibilities Programmes, 2005.

[17] Organisation for Economic Co-operation and Development. (OECD). Extended Producer Responsibility. Guidance Manual for Govern, 2001.

[18] Walls M. The Role of Economics in Extended Producer Responsibility: Making Policy Choices and Setting Policy Goals. Resources for the Future. 2003.

[19] Tibben-Lembke R.S, Rogers D.S. Differences between forward and reverse logistics in a retail environment. Supply Chain Management; 7; 2002, p. 271-282.

[20] Stock, James R., "Reverse Logistics in the Supply Chain,” Business Briefing: Global Purchasing \& Supply Chain Management. October, pp. 44-48, 2001.

[21] Hicks, C, Heidrich, O. Mcgovern, T. And Donnelly, T., “A Functional Model of Supply Chains and Waste”, Intern'l Journal Production Economics. 89: 165-174, 2004.

[22] González-Torre P.L, Adenso-Diaz B., Artiba H. Environmental and reverse logistics policies in European bottling and packing firms. International Journal of Production Economics. 88, 2004. p. 95-104.

[23] Dowlatshahi, S. Developing a theory of reverse logistics. Interfaces, v. 30, n. 3, p. 143-155, 2000.

[24] Jahre, M. Household waste collection as reverse channel - a theoretical perspective. Intern. Journal Physical Distribution and Logistics Management, v. 25, n. 2, p. 39-56, 1995.

[25] Jahre, M. The logic costs of collecting recyclable household waste modeling systems for cost consequence analysis. International Workshop of Systems Engineering Models for Waste Management, Göteborg, Sweden, 1998 apud VEIGA, 2009.

[26] Bucklin L.P., "Postponement, Speculation and Structure of Distribution Channels”, Journal of Marketing Research. Feb. pp. 26-31, 1965. 
[27] Pagh J.D., Cooper, M.C., "Supply Chain Postponement and Speculation Strategies: How to Choose the Right Strategy", Journal of Business Logistics, Vol. 19, 2: pp. 13-33. 1998.

[28] Veiga, M.M. Flaws in Brazilian take-back program for pesticide containers in a small rural community. Management Research News, v. 32, n. 1, p. 62-77, 2009.

[29] Krikke, H., Pappis, C. P., Tsoulfas G. T. and Bloemhof-Ruwaard J., "Design Principles for Closed Loop Supply Chains: Optimizing Economic, Logistic and Environmental Performance”, ERIM Report Series Reference No. ERS-2001-62-LIS. Working Paper Series. Available at http://papers.ssrn.com, 2001. 